\title{
CQA 206-291 in Parkinson's Disease: An Acute Single Escalating Dosage Study
}

\author{
Anthony E. Lang, David E. Riley, Luc Vachon and Xavier Lataste
}

\begin{abstract}
CQA 206-291, a new ergot derivative with a "biphasic" dopaminergic profile, was studied in 6 patients with longstanding Parkinson's disease suffering from pronounced fluctuations in hourly mobility. On alternate days, up to seven single doses, escalating from 0.2 to $20 \mathrm{mg}$, were given as replacement for the usual first morning dose of levodopa. At the most effective dosage, four of the six patients obtained as good a peak response to CQA (8-20 mg) as to L-dopa. Side effects were common and similar to other ergot derivatives, suggesting that the initial weak dopamine antagonist properties of the parent compound, documented in animals, may be of little clinical significance. However, comparative studies will be needed to confirm this suspicion. The addition of domperidone successfully reduced the incidence and severity of side effects. CQA 206-291 has potent anti-parkinsonian properties; further longer-term treatment trials are indicated.
\end{abstract}

RÉSUMÉ: Le CQA 206-291 dans la maladie de parkinson: une étude à court terme à dosage progressif Le CQA 205-291, un nouveau dérivé de l'ergot ayant un profile dopaminergique "biphasique", a été étudié chez 6 patients atteints de la maladie de Parkinson depuis plusieurs années et présentant des fluctuations marquées de la mobilité d'heure en heure. A tous les deux jours, nous avons donné des doses croissantes allant de 0.2 à $20 \mathrm{mg}$, en plusieurs prises (jusqu'a sept), en remplacement de la première dose matinale habituelle de L-dopa. À la dose la plus efficace, quatre des six patients ont obtenu une réponse maximale aussi bonne avex le CQA (8-20 mg) qu'avec la L-dopa. Les effets secondaires ont été fréquents et semblables à ceux des autres dérivés de l'ergot, suggérant que la propriété du composé mère qui agit comme un antagoniste faible de la dopamine chez l'animal comporte possiblement peu de signification clinique. Cependant, des études comparatives seront nécessaires pour comfirmer ce soupçon. L'ajout de dompéridone a diminué l'incidence et la sévérité des effets secondaires. Le CQA 206-291 a des propriétés anti-parkinsoniennes puissantes; il s'avère pertinent de procéder à des essais thérapeutiques à long terme.

Can.J. Neurol. Sci. 1990; 17:416-419

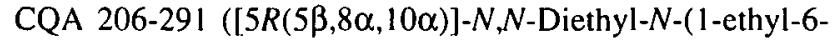
methyl-ergoline-8-y1) sulfamide hydrochloride) is an ergot derivative with "biphasic" dopaminergic properties. The parent drug is a weak D2 antagonist which is metabolized to CQ 32084, a potent agonist for both D2 and D1 receptors.' We have assessed the clinical response to single increasing oral doses of CQA 206-291 in patients with Parkinson's disease suffering from pronounced fluctuations in mobility on long-term levodopa therapy. The response was compared to the effects of their usual dosage of levodopa.

\section{Patients and Methods}

Six patients with idiopathic Parkinson's disease were studied. The patient characteristics are listed in Table 1. All patients were experiencing motor fluctuations despite multiple levodopa doses throughout the day. These patients were chosen because all had predictable morning akinesia and easily measurable, well defined short to medium duration responses to levodopa. Only one patient (Patient 4) was taking an additional antiparkinsonian medication at the time of the study (amantadine $100 \mathrm{mg}$ tid) and this was continued through the study (Table 1).

CQA 206-291 was given orally on alternate days (i.e., Monday, Wednesday, Friday) with the patients' usual levodopa (as Sinemet) treatment continued on the intervening days. Levodopa was stopped the evening before each study day and the patient fasted overnight. The following morning, CQA 206291 was administered orally beginning in a dosage of $0.2 \mathrm{mg}$ and increasing on subsequent trials through $0.5,1.0,2.0,4.0$, $8.0,15$ and $20 \mathrm{mg}$. Parkinsonian motor disability was rated using the motor score (section 3) of the Unified Parkinson's Disease Rating Scale (UPDRS) ${ }^{2}$ prior to drug administration and at $0.5,1.0,1.5,2.0$ and 3.0, and if necessary 4.0, 5.0 and 6.0 hours afterward. If there was no response within three hours of receiving CQA 206-291 or if benefit had worn off before the end of 6 hours, then the trial was abbreviated. Patients resumed the usual levodopa treatment, beginning with their first standard morning dosage. Supine and standing blood pressure, pulse and side effects were recorded at each of the examination time intervals. Serum biochemistry and hematology were assessed at the

From the Movement Disorders Clinic, Toronto Western Hospital, 25 Leonard Ave., 101, Toronto, Ontario

Received April 9, 1990. Accepted in final form July 24, 1990

Reprint requests to: Dr. A.E. Lang, Movement Disorders Clinic, Toronto Western Hospital, 25 Leonard Ave., 101, Toronto, ON Canada M5T 2R2 


\begin{tabular}{|c|c|c|c|c|c|c|}
\hline $\begin{array}{l}\text { Patient } \\
\text { No. }\end{array}$ & Age & Sex & $\begin{array}{c}\text { Duration of } \\
\text { Disease (yrs.) }\end{array}$ & Previous Therapy & $\begin{array}{c}\text { Schwab } \\
\text { England } \\
\text { ADL (off/on) }\end{array}$ & $\begin{array}{c}\text { Levodopa/Carbidopa } \\
\text { dosage } \\
\text { (mg/day) }\end{array}$ \\
\hline 1 & 67 & $\mathbf{M}$ & 14 & $\begin{array}{l}\text { amantadine } \\
\text { bromocriptine }\end{array}$ & $30 / 65$ & $900 / 90$ \\
\hline 2 & 75 & F & 30 & $\begin{array}{l}\text { amantadine } \\
\text { levodopa-benserazide } \\
\text { trihexyphenidyl } \\
\text { ethopropazine } \\
\text { bromocriptine } \\
\text { pergolide } \\
\text { deprenyl }\end{array}$ & $50 / 70$ & $600 / 150$ \\
\hline 3 & 56 & $F$ & 8 & $\begin{array}{l}\text { amantadine } \\
\text { trihexyphenidyl } \\
\text { bromocriptine } \\
\text { pergolide }\end{array}$ & $40 / 75$ & $1600 / 400$ \\
\hline 5 & 58 & $M$ & 6 & $\begin{array}{l}\text { amantadine } \\
\text { bromocriptine }\end{array}$ & $60 / 90$ & $1800 / 450$ \\
\hline 6 & 62 & $M$ & 16 & $\begin{array}{l}\text { amantadine } \\
\text { trihexyphenidyl } \\
\text { bromocriptine }\end{array}$ & $10 / 90$ & $1350 / 337.5$ \\
\hline
\end{tabular}

Schwab and England ADL scores are percentages of normal functioning in the "off" and "on" phases provided by patient and relatives using the Activities of Daily Living Scale subsection 6 of the UPDRS (reference 2).

*Patient 4 continued on amantadine through the course of the study.

beginning of the study and 24 hours after each dose of the experimental drug. Electrocardiogram was obtained before the study and again 2 to 3 hours after each dose of CQA 206-291. Complete general and neurological examinations were performed before and after the study.

The patients' motor response to their usual morning dosage of levodopa, also given after withholding medication overnight, was assessed during the course of the study on four separate occasions in five patients and three times in the sixth (Patient 3 ).

When patients experienced "peripheral" side effects such as nausea, vomiting, or hypotension in response to one dose of CQA 206-291, domperidone $20 \mathrm{mg}$ was given by mouth $30-60$ minutes before their subsequent doses. In Patient 1 the dose of $2.0 \mathrm{mg}$ of CQA 206-291 caused side effects and was administered again a second time on the next experimental day, whereas the remaining patients continued to follow the dosage increment schedule.

\section{RESULTS}

All six patients obtained a marked improvement in their parkinsonian motor scores after their usual morning dosage of levodopa (as Sinemet). The far left bars in each component of Figure 1 provide the mean (of 4 trials in 5 patients and 3 trials in 1 patient) percentage improvements in motor score in response to levodopa for the individual patients.

Figure 1 also gives the maximum percentage of reduction in motor score in each patient for the individual doses of CQA administered. Minimal or no improvement in Parkinson motor scores were seen with dosages under $2.0 \mathrm{mg}$. One patient (Case 4) obtained a good partial response to $2.0 \mathrm{mg}$, responded less well to 4.0 and $8.0 \mathrm{mg}$ and then had maximum benefit at 15 and
$20 \mathrm{mg}$ but still did not improve as much as with her usual dosage of levodopa. On the other hand, the duration of benefit from $20 \mathrm{mg}$ was 5 hours in comparison to her usual 2 hour response to Sinemet. One patient (Case 5) had a very brief partial response to $4.0 \mathrm{mg}$ but no benefit with higher dosages. (This patient experienced severe off periods in response to minimal emotional stress. He found participation in the study, particularly the in-patient requirement, extremely stressful and it was felt that this contributed to his failure to experience benefit. He is considered a drug failure.) Two patients obtained a good response to $8.0 \mathrm{mg}$. One of these (Case 1) developed confusion following his response and so he was withdrawn from further study while the second (Case 2) had a brief response to $8 \mathrm{mg}$, failed to respond to $15 \mathrm{mg}$ and obtained a partial (but good) response to $20 \mathrm{mg}$ lasting 2.5 hours with mild dyskinesias persisting for a further 4 hours. In one patient $15 \mathrm{mg}$ resulted in a brief ( $10 \mathrm{~min}$.) period of dyskinesias but parkinsonism failed to improve. Because of intolerable side effects, the $20 \mathrm{mg}$ dosage was not administered (Case 3). The final patient (Case 6) obtained an excellent response only with $20 \mathrm{mg}$.

In the 4 patients responding to CQA 206-291 benefit occurred 1.5-3.0 hours after drug ingestion and lasted 1.5-5 hours (mean 2.6 hours). In the same four CQA responders, levodopa responses occurred with a latency of 0.5-1.5 hours (mean 0.7 hours) and had a mean duration of 2.25 hours (range 2.0-2.5 hours). In these patients, the maximum percent reductions in total UPDRS motor score and subscores for tremor, rigidity and limb bradykinesia obtained with CQA were equivalent to the mean responses obtained with levodopa (50\% vs. $49 \%, 100 \%$ vs. $93 \%, 53 \%$ vs. $52 \%$ and $43 \%$ vs. $46 \%$, respectively).

Side effects were common. Supine mean arterial blood pressure fell in all patients with a further decrease occurring upon 

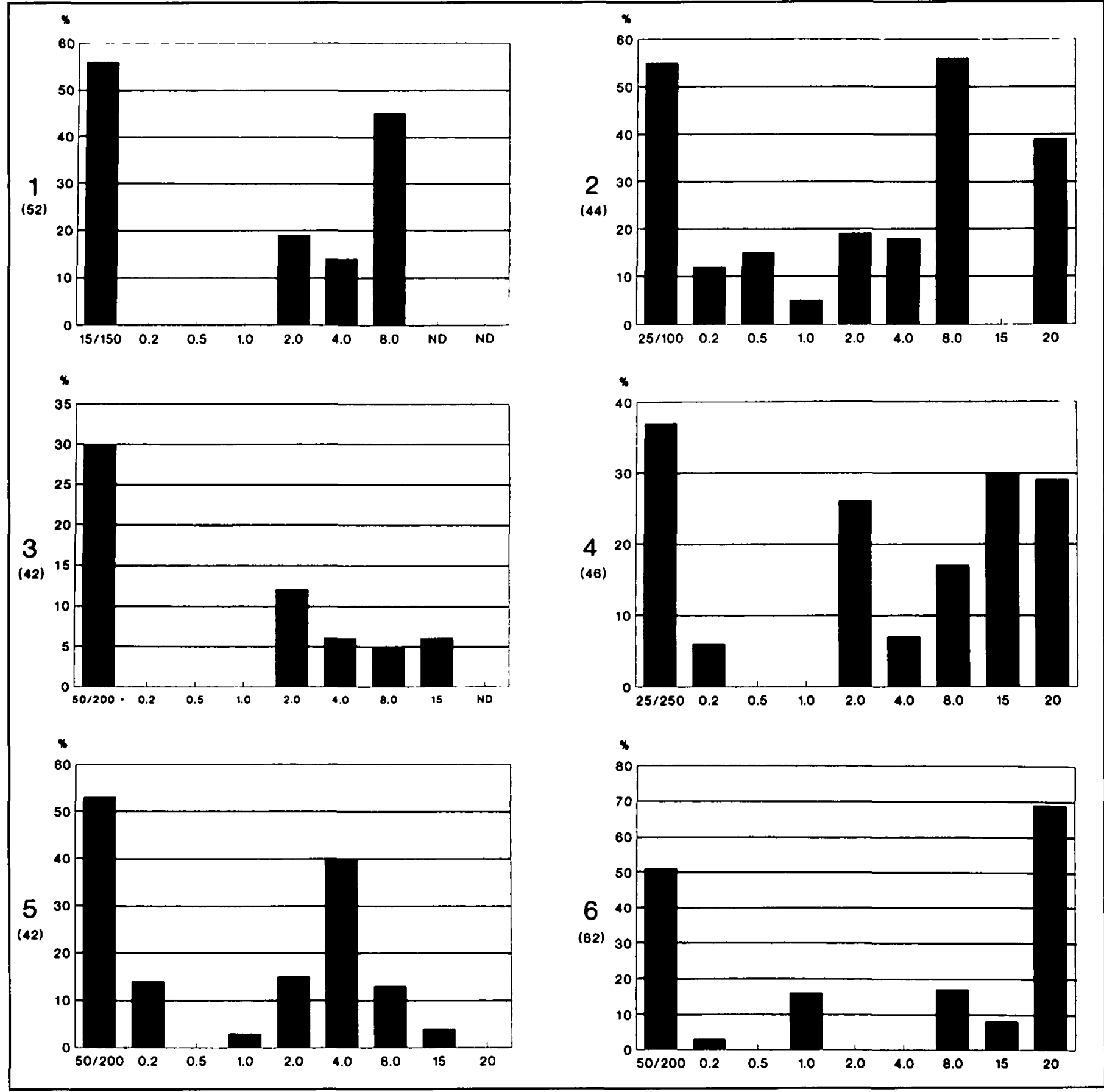

Figure I - Improvement in Motor Score on CQA 206-29I and Levodopa. Bargraphs indicate the maximum percent reduction in total UPDRS motor scores $^{2}$ with Sinemet or CQA 206-29l in varying doses in the 6 patients studied. The patient number is given at the left side of each graph and below this in parenthesis is the mean baseline total UPDRS motor score for each. The far left bar represents the mean maximum response to 4 separate trials of Sinemet (individual dosage at the base of the bar). $1^{*}=$ mean of 3 trials in patient 3:0.2-20. $=C Q A$ dosages; $N D=n o t$ done).

standing. Patient 6 was so akinetic in the off period that it was impossible for him to stand even with assistance. In all other patients, the orthostatic fall in blood pressure was symptomatic, experienced at a dose of $1 \mathrm{mg}$ in three and $2 \mathrm{mg}$ in the other two. Two patients were unable to stand because of orthostatic hypotension; one of these had a simultaneous pronounced fall in supine mean arterial blood pressure $(70 \mathrm{mmHg}$ ) and the second had only a mild change $(18 \mathrm{mmHg})$. Domperidone significantly attenuated the effects on both supine and standing blood pressure and completely prevented the subjective sensation of orthostatic faintness. Other side effects are listed in Table 2. The addition of domperidone markedly reduced or completely prevented "peripheral" side effects such as hypotension, gastrointestinal intolerance, flushing, and nasal congestion experienced with earlier doses. As the dose was increased further, side effects again became common. However, subsequent "peripheral" 
Table 2: Side Effects of CQA 206-291

\begin{tabular}{lcc}
\hline Side Effect & Number of Patients & $\begin{array}{r}\text { Dose in mg at which } \\
\text { SE first appeared } \\
\text { (no. of patients) }\end{array}$ \\
\hline $\begin{array}{l}\text { Hypotension/ } \\
\text { Postural dizziness }\end{array}$ & 5 & $1.0(3)$ \\
Nausea & 5 & $2.0(2)$ \\
& & $1.0(3)$ \\
Vomiting & 2 & $20.0(2)$ \\
Dyskinesias & 5 & $1.0(1)$ \\
& & $15.0(1)$ \\
& & $2.0(2)$ \\
Drowsiness (usually & 4 & $4.0(1)$ \\
with hypotension) & & $8.0(1)$ \\
Hot flushes/sweating & 2 & $15.0(1)$ \\
& & $1.0(4)$ \\
Loose stool/Diarrhea & 2 & $2.0(1)$ \\
& & $20.0(1)$ \\
Nasal congestion & 1 & $4.0(1)$ \\
"Weakness" in legs & 1 & $15.0(1)$ \\
Confusion & 1 & 1.0 \\
\hline
\end{tabular}

complications prevented proceeding to the maximum dosage in only onc patient. Central nervous system side effects included dyskinesias identical to those experienced with levodopa ( 5 patients) and confusion (in 1 patient who had previously experienced hallucinations on bromocriptine). There were no significant hematological, biochemical or electrocardiographic changes seen throughout the study.

\section{Discussion}

This study was designed to assess the efficacy and tolerability of alternate day single increasing oral doses of CQA 206-291 after overnight levodopa withdrawal in six patients with Parkinson's disease experiencing pronounced fluctuations in hourly mobility. We found that four of these six patients obtained as good a peak response with CQA 206-291 at the most effective dose $(8-20 \mathrm{mg})$ as with their usual morning dosage of levodopa. This is somewhat unusual for the ergot class of direct acting dopamine agonists since most studies have found that patients rarely obtain a response equivalent to that seen with levodopa. In general, the peak efficacy and duration of response were dose related. However, we did not find as obvious a correlation between dosage and efficacy as Temlett et $\mathrm{a}^{3}{ }^{3}$ in their recent report of a similar study. There was a latency of 1.5 to 3 hours between drug ingestion and response whereas the same patients usually turned "on" in $0.5-1.5$ hours (mean 0.7 hours) in response to levodopa. The duration of effect of CQA was slightly longer than that obtained in the same patients with Sinemet (2.6 vs. 2.25 hours). Studies of larger numbers of patients treated chronically (attaining stable plasma levels) would be required before it could be determined whether these differences are truly significant. One patient failed to benefit from the maximum dosage of $20 \mathrm{mg}$. However, his emotional state may have accounted in part for this failure. Another patient dropped out after experiencing pronounced side effects from $15 \mathrm{mg}$. Importantly, two responding patients had not obtained maximal benefit until reaching the $20 \mathrm{mg}$ dosage and one of these had obtained no benefit until that point. One interesting observation was the apparent lower threshold for dyskinesias than for the therapeutic benefit. This might relate to a different profile of dopamine receptor stimulation with CQA than with levodopa. However, since there is considerable controversy regarding the mechanisms underlying dyskinesias, ${ }^{4}$ further explanation of the present observation would be conjectural.

The side effect profile of CQA 206-291 is similar to that of other ergot-derivative dopamine agonists. This suggests that the initial weak dopamine antagonist properties of the parent compound documented in animals may be of little clinical significance. However, comparative studies with other ergol derivatives, using a slow, continuous titration schedule as normally used in the clinic, would be necessary to confirm this suspicion. The peripheral dopamine receptor antagonist domperidone was extremely effective in controlling such common side effects as hypotension and gastrointestinal intolerance. The ameliorative effect on CQA-induced early hypotension was pronounced in all patients experiencing this complication. For example, hypotension severe enough to preclude standing occurred in 2 patients with 1.0 and $2.0 \mathrm{mg}$ respectively. This was completely avoided 2 days later when the patients were challenged with the same or higher doses of CQA 206-291 preceded by domperidone. However, with the rapidly escalating dosage schedule and intermittent administration as used, side effects frequently recurred at higher dose levels despite domperidone. As with other dopamine agonists, it is likely that a slower continuous titration of the drug will considerably improve tolerability.

We conclude that CQA 206-291 has potent antiparkinsonian properties. In agreement with the recent report of Temlett et al.,3 this drug given alone in adequate dosages produces a pronounced improvement in most patients with Parkinson's disease. The latency from intake to response is longer than that seen with levodopa. However, the degree of benefit may be equivalent and duration of response slightly longer than that obtained with the same patient's usual dosage of levodopa. These initial promising results should encourage further studies of CQA 206-291 to determine its value in the chronic treatment of Parkinson's discase.

\section{ACKNOWLEDGEMENTS}

Thanks to Ms. B. Reid and Miss C. Kierans for assistance with the study, Miss J. Murphy for assistance in assessment of the data, and Mrs. J. Lennox for typing the manuscript.

Note added in proof: Since completion of the study and acceptance of this manuscript, Sandoz Pharma Lid. has discontinued further clinical development of CQA 206-29l because of recent animal toxicological findings.

\section{REFERENCES}

1. Jaton AL, Enz A, Vigouret JM, et al. CQA 206-29l, an ergot derivative with biphasic dopaminergic action. Experimentia 1987; 43: 705.

2. Lang AE, Fahn S. Assessment of Parkinson's disease. In: Munsat TL, ed. Quantification of Neurological Deficit. Boston: Butterworths 1989; 285-309.

3. Temlett JA, Quinn NP, Marsden CD, et al. The antiparkinsonian activity of CQA 206-291, a new $D_{2}$ dopamine receptor agonist. Clin Neuropharmacol 1989; 12: 55-59.

4. Nutt JG. Levodopa-induced dyskinesia: review, observations, and speculations. Neurology 1990; 40: 340-345. 